\title{
Commentary: Early Clinical Indicators of Addison's Disease in Adults With Type 1 Diabetes: A Nationwide, Observational, Cohort Study
}

\author{
Jan Brož ${ }^{1 *}$, Jana Urbanová ${ }^{2,3}$, Katarina Halčiaková ${ }^{1}$, Marisa A. Nunes ${ }^{1}$ and \\ Ludmila Brunerová ${ }^{2,3}$ \\ ${ }^{1}$ Department of Internal Medicine, Second Faculty of Medicine, University Hospital Motol Charles University, Prague, \\ Czechia, ${ }^{2}$ Center for Research of Diabetes, Metabolism and Nutrition, Prague, Czechia, ${ }^{3}$ Second Department of Internal \\ Medicine, Third Faculty of Medicine, University Hospital Královské Vinohrady, Prague, Czechia
}

Keywords: type 1 diabetes mellitus, Addison's disease, screening, diabetic complications, severe hypoglycaemia

\section{OPEN ACCESS}

Edited by:

Thozhukat Sathyapalan, University of York, United Kingdom

Reviewed by:

Harshal Deshmukh, University of Hull, United Kingdom

*Correspondence:

Jan Brož

zorb@seznam.cz

Specialty section: This article was submitted to

Diabetes,

a section of the journal

Frontiers in Endocrinology

Received: 11 February 2019

Accepted: 24 June 2019

Published: 09 July 2019

Citation:

Brož J, Urbanová J, Halčiaková K

Nunes MA and Brunerová L (2019)

Commentary: Early Clinical Indicators of Addison's Disease in Adults With

Type 1 Diabetes: A Nationwide,

Observational, Cohort Study.

Front. Endocrinol. 10:456

doi: $10.3389 /$ fendo.2019.00456

\section{A Commentary on}

Early Clinical Indicators of Addison's Disease in Adults with Type 1 Diabetes: A Nationwide, Observational, Cohort Study

by Chantzichristos, D., Persson, A., Miftaraj, M., Eliasson, B., Svensson, A. M., and Johannsson, G. (2018). J. Clin. Endocrinol. Metab. 104, 1148-1157. doi: 10.1210/jc.2018-02064

We read with great interest the article by Chantzichristos et al. (1) published in the Journal of Clinical Endocrinology and Metabolism. The paper presents the results of an observational, matched-cohort study which set out to determine whether there are any early clinical indicators for the onset of Addison's disease (AD) in adults with type 1 diabetes mellitus (T1DM). In the first part of the study, the authors analyzed many variables within a period of 2 years before diagnosis of AD in 66 T1DM patients, using data from several registries. Comparisons were made with 330 controls, matched for age, sex, and duration of diabetes. It was concluded that the presence of medical treatment for thyroid disease, a severe infection (expressed as necessity of hospital admission), and glucagon prescription for severe hypoglycemia should raise the suspicion of AD development in adults with T1DM. A significantly higher prevalence of diabetic retinopathy was also found in T1DM patients with AD.

The authors should be congratulated on their efforts to collect and analyse such a large amount of data and trying to correct for important covariables, leading to an interesting debate and highlighting this very important topic.

Although we agree with many of the conclusions of this interesting and important study, we would like to make at least four comments.

First, we understand that the authors consider the glucagon prescription as a sort of sign of severe hypoglycemia. However, it should be noted that this is only its indirect marker (2). Furthermore, although severe hypoglycemia was occasionally reported as a symptom of $\mathrm{AD}$ in TIDM patients (3-5), the study which aimed to screen for $\mathrm{AD}$ in patients with recurrent severe hypoglycemia failed to demonstrate the value of this as a screening test for the disease (6). Therefore, we would like to respectfully suggest investigating whether two or all three features mentioned in the conclusion are not clustering together in any of the patients in the $\mathrm{AD}$ group 
and compare it with those in the control group, as this could reveal another and probably more powerful marker of AD.

Second, it would be interesting to see not only one value of $\mathrm{HbAlc}$ but its full course during those 2 years before $\mathrm{AD}$ diagnosis. Its analysis may discover a possible impairment and thus find another marker of AD.

Third, although the prescriptions of various drugs were analyzed insulin was not involved. As a reduction in insulin dose was described as one of the possible signs of AD (7), analysis of the change in dose could reveal other important results.

Fourth, the prevalence of retinopathy (22.7\%) in the AD group with even smaller number in the control group (13.6\%) is much lower than that which was found, for example, in a Swedish population-based cross-sectional study (40\%) conducted in a study population with similar mean diabetes duration (8). This difference may lead us to speculate whether the data in the registry reflect the real prevalence of diabetic retinopathy in the T1DM population.

\section{REFERENCES}

1. Chantzichristos D, Persson A, Miftaraj M, Eliasson B, Svensson AM, Johannsson G. Early clinical indicators of Addison's disease in adults with type 1 diabetes: a nationwide, observational, cohort study. J Clin Endocrinol Metab. (2018) 104:1148-57. doi: 10.1210/jc.2018-02064

2. Fendrick AM, He X, Liu D, Buxbaum JD, Mitchell BD. Glucagon prescriptions for diabetes patients after emergency department visits for hypoglycemia. Endocr Pract. (2018) 24:861-6. doi: 10.4158/EP-2018-0223

3. Passanisi S, Timpanaro T, Lo Presti D, Caruso-Nicoletti M. Recurrent hypoglycaemia in type-1 diabetes mellitus may unravel the association with Addison's disease: a case report. BMC Res Notes. (2014) 7:634. doi: 10.1186/1756-0500-7-634

4. McAulay V, Frier BM. Addison's disease in type 1 diabetes presenting with recurrent hypoglycaemia. Postgrad Med J. (2000) 7:230-2. doi: 10.1136/pmj.76.894.230

5. Thomas JB, Petrovsky N, Ambler GR. Addison's disease presenting in four adolescents with type 1 diabetes. Pediatr Diab. (2004) 5:20711. doi: 10.1111/j.1399-543X.2004.00056.x
We respectfully suggest taking these points into account especially if a continuation of this important study is planned.

\section{AUTHOR CONTRIBUTIONS}

JB designed and wrote the commentary. JU, KH, MN, and LB contributed to the design and revised the text critically for important intellectual content.

\section{FUNDING}

This article was supported by the Ministry of Health, Czech Republic-conceptual development of research organization, Motol University Hospital, Prague (Czech Republic 00064203).

\section{ACKNOWLEDGMENTS}

Special thanks to Dion Pritchard for language editing.

6. Likhari T, Magzoub S, Griffiths MJ, Buch HN, Gama R. Screening for Addison's disease in patients with type 1 diabetes mellitus and recurrent hypoglycaemia. Postgrad Med J. (2007) 83:420-1. doi: 10.1136/pgmj.2007.058321

7. Armstrong L, Bell PM. Lesson of the week: Addison's disease presenting as reduced insulin requirement in insulin dependent diabetes. BMJ. (1996) 3:1601.

8. Färnkvist LM, Lundman BM. Outcomes of diabetes care: a population-based study. Int J Qual Health Care. (2003) 15:301-7. doi: 10.1093/intqhc/mzg047

Conflict of Interest Statement: The authors declare that the research was conducted in the absence of any commercial or financial relationships that could be construed as a potential conflict of interest.

Copyright (C) 2019 Brož, Urbanová, Halčiaková, Nunes and Brunerová. This is an open-access article distributed under the terms of the Creative Commons Attribution License (CC BY). The use, distribution or reproduction in other forums is permitted, provided the original author(s) and the copyright owner(s) are credited and that the original publication in this journal is cited, in accordance with accepted academic practice. No use, distribution or reproduction is permitted which does not comply with these terms. 